\title{
Low-Risk Prostate Cancer and Tumor Upgrading in the Surgical Specimen: Analysis of Clinical Factors Predicting Tumor Upgrading in a Contemporary Series of Patients Who were Evaluated According to the Modified Gleason Score Grading System
}

\author{
Antonio B. Porcaro ${ }^{\mathrm{a}} \quad$ Salvatore Siracusano ${ }^{\mathrm{a}} \quad$ Nicolò de Luyk $^{\mathrm{a}} \quad$ Paolo Corsi $^{\mathrm{a}}$ \\ Marco Sebben $^{\mathrm{a}} \quad$ Alessandro Tafuri $^{\mathrm{a}} \quad$ Daniele Mattevi $^{\mathrm{a}} \quad$ Leonardo Bizzotto $^{\mathrm{a}}$ \\ Irene Tamanini $^{\mathrm{a}} \quad$ Maria A. Cerruto $^{\mathrm{a}} \quad$ Guido Martignoni $^{\mathrm{b}} \quad$ Matteo Brunelli $^{\mathrm{b}}$ \\ Walter Artibani ${ }^{\mathrm{a}}$ \\ aUrologic Clinic; b Department of Patholog, University Hospital, Ospedale Policlinico, Azienda Ospedaliera Universitaria Integrata, \\ Verona, Italy
}

\section{Key Words}

Prostate cancer $\cdot$ Low risk $\cdot$ Tumor grade $•$

Tumor upgrading $\cdot$ Gleason score system

\begin{abstract}
Objective: To identify significant clinical factors associated with prostate cancer ( $\mathrm{PCa}$ ) upgrading the low-risk PCa patients graded according to the modified Gleason score system. Materials and Methods: The logistic regression model was used to evaluate the records of 438 patients. Results: There were 170 cases (38.8\%) of low-risk PCa and tumors were upgraded in 111 patients (65.3\%). Only prostate specific antigen (PSA) and the proportion of positive cores $(\mathrm{P}+)$ were independent predictors of tumor upgrading. Further exploration was investigated by categorizing and regressing PSA $(\leq 5.0$ vs. $>5.0 \mathrm{ng} / \mathrm{ml})$ and $P+(\leq 0.20$ vs. $>0.20)$. The odds ratio of PSA $>5 \mathrm{ng} / \mathrm{ml}$ was 1.32 and of $\mathrm{P}+>0.20$ was 2.71 . The population was stratified into very low-risk with PSA $\leq$ $5 \mathrm{ng} / \mathrm{ml}$ and $\mathrm{P}+\leq 0.20$ (class A), low-risk with PSA $>5 \mathrm{ng} / \mathrm{ml}$
\end{abstract}

\section{KARGER}

(C) 2016 S. Karger AG, Basel

Fax +4161306 1234

E-Mail karger@karger.com

www.karger.com
Accessible online at:

www.karger.com/cu and $\mathrm{P}+\leq 0.20$ (class B), intermediate risk with PSA $\leq 5 \mathrm{ng} /$ $\mathrm{ml}$ and $\mathrm{P}+>0.20$ (class $\mathrm{C}$ ), and high risk with PSA $>5 \mathrm{ng} / \mathrm{ml}$ and $P+0.20$ (class $D$ ). Upgrading rates were extremely low in class A (9\%), extremely high in D (50.5\%), and moderate (20\%) in B and C. Conclusion: Patients diagnosed with lowrisk PCa at biopsy are a heterogeneous population because they include subsets with undetected high-grade disease. Significant clinical predictors of upgrading include the PSA value and $\mathrm{P}+$. In low-risk PCa, we identified a high-risk upgrading subgroup that needed repeat biopsies in order to reclassify the tumor grade and to reassess the clinical risk category.

Copyright $\odot 2016$ S. Karger AG, Basel

\section{Introduction}

The number of patients diagnosed with prostate cancer $(\mathrm{PCa})$ and classified in the low-risk category by the D'Amico criteria [1] is decreasing by $29 \%$ per year since 
the recommendation against screening. However, in low-risk patients, $\mathrm{PCa}$ is diagnosed at an early stage and shows a natural history which is often slowly progressive or non-progressive and thus unlikely to cause morbidity or death [2]. Since radical prostatectomy (RP) and radiotherapy are the standard active treatments for organ confined $\mathrm{PCa}$, harm from over-diagnosis and over-treatment are a significant concern in low-risk PCa patients harboring an indolent and non-progressive or slowly-progressive disease [3].

Active surveillance is the management that is increasingly being used as a strategy to avoid or delay the potential harm caused by unnecessary radical treatment in PCa patients who are unlikely to progress [4]. The Gleason grading system, which is the most effective factor in predicting the natural history of $\mathrm{PCa}$, has been modified in recent years and is able to identify more homogenous, truly low-grade cancers [5-8].

It has been shown that the risk of lymph node metastases is only $0.48 \%$ in pure Gleason score 6 cancers defined according to these criteria [9]. However, there is heterogeneity within this population because several RP historical series, which date before the modification of the Gleason grading system, showed an important risk of upgrading which ranged between $30 \%$ and $40 \%$ [10-12]. Moreover, cancer upgrading is a negative prognostic factor [13]. As a consequence, low-risk PCa patients who would have been pathologically upgraded are unfit for less invasive observational strategies such as active surveillance or watchful waiting [3].

Patient-risk misclassification in the clinically localized low-risk PCa is a critical issue and the identification of clinical risk factors predicting tumor upgrading will help clinicians with the assessment of pathologically intermediate-risk or high-risk patients who need active treatment to cure the disease. The aim of the present study was to identify significant clinical factors, if any, associated with the tumor upgrading of surgical specimens in recent and contemporary series of low-risk PCa patients who were graded according to the modified Gleason score system.

\section{Materials and Methods}

We reviewed the records of 456 patients who underwent RP by robot-assisted or retropubic approach with or without extended lymph node dissection at our institution during the period between January 2013 and June 2014. We excluded 18 patients because of androgen deprivation therapy $(n=15)$, pT0 $(n=1)$, other histology (

Low-Risk Prostate Cancer and Tumor Upgrading tion and use of patient data, who signed informed consent, had Institutional Board Review approval. All data were prospectively collected and retrospectively analyzed.

The term low-risk PCa was defined as the risk status for patients who have a Gleason score $\leq 6$, prostate specific antigen (PSA) $<10 \mathrm{ng} / \mathrm{ml}$, and $\leq$ stage T2a according to the D'Amico risk classification of PCa [1].

The main indications to perform prostate biopsies were abnormal age specific levels of PSA and/or an abnormal digital rectal exam. Prostate biopsies were not all performed at our institution. Prostate biopsies performed elsewhere were accepted after assessing the following minimum inclusion criteria: (i) at least 12-14 biopsy cores, (ii) the number of positive cores, (iii) grading of PCa according to the modified Gleason score system (biopsy Gleason score: bGS), and (iv) measurement of prostate volume $(\mathrm{ml})$. In the present analysis, we considered the proportion of positive cores $(\mathrm{P}+)$, the modified bGS, and prostate volume. In our institution, the 14-core transperineal guided prostate biopsy technique is routinely used and additional cores are taken when a lesion on either transrectal ultrasound, digital rectal examination or magnetic resonance imaging (MRI) is evident. However, in the present study, we did not considered additional cores of suspected lesions and thus the analysis including the ratio of the positive cores to the total (proportion of positive cores) was not skewed. Although transrectal biopsies are the standard, in our institution because of historical reasons prostate biopsies are performed by the transperineal approach and are not template guided. Prostate volume was measured by standard methods and the PSA density was calculated. The biopsy cores acquired at our institution and the RP specimens were assessed by dedicated pathologists. In each biopsy core, the pathologists systematically assessed the following issues: (i) length, (ii) detection and grade of $\mathrm{PCa}$ according to the new Gleason score system (bGS), (iii) length of the biopsy core involved by $\mathrm{PCa}$, (iv) prostatic intraepithelial neoplasia, (v) chronic inflammatory infiltrate, (vi) glandular atrophy, and (vii) atypical small acinar cell proliferation. In the present analysis, we considered $\mathrm{P}+, \mathrm{bGS}$, and the prostate volume. The proportion of positive cores $(\mathrm{P}+)$ was calculated as the ratio of the number of positive cores to the total number of cores acquired.

The removed prostates were assessed by dedicated pathologists as follows. The prostatectomy specimens were fixed overnight (10\% neutral buffered formaldehyde), coated with India ink, and then weighed. Tissue sections of $4 \mu \mathrm{m}$ were prepared in the standard fashion and stained with hematoxylin and eosin. All specimens were processed according to the Stanford protocol. Patients were classified according to primary tumor stage, lymph node, and metastatic status, using the American Joint Committee on Cancer TNM classification system. Seminal vesicle invasion was defined as tumor involvement of the muscolar wall (pT3b). Bladder neck invasion was staged as pT3a. Surgical margins (R) were stated as free (R0) or involved by cancer (R1). Tumors were graded according to the modified Gleason grading system and the pathology Gleason score (pGS) was computed after summing up the 2 patterns (pGP), prevalent and secondary, of the tumor [5-8]. The tertiary Gleason patterns were not considered in the present analysis. The pathological extension of the tumor was measured as the percentage of cancer related to the volume of the prostate and coded as $\mathrm{V}+(\%)$.

In the present analysis, the following variables were considered: $\mathrm{V}+, \mathrm{pGS}, \mathrm{pGP}, \mathrm{pT}$, and $\mathrm{pN}$. Age (years) and body mass index $\left(\mathrm{BMI}, \mathrm{kg} / \mathrm{m}^{2}\right)$ were calculated for each patient. PSA was measured 
by immunochemiluminescent test performed by the ADVIA Centaur XP Immunoassay System (Siemens Company). The variables were grouped as clinical (age, BMI, PSA, prostate volume, bGS, $\mathrm{P}+$ ) and pathological (pGS, pGP, pN).

\section{Statistical Methods}

The entire cohort, assessed by continuous and categorical variables, was classified into 2 groups that included cases that were pathologically upgraded because of a $\mathrm{pGP}>3+3$ and patients who were not upgraded because of a $\mathrm{pGP}=3+3$. Data on continuous variables are presented as mean \pm SD and medians with their respective ranges. Differences between groups were analyzed with the Mann-Whittney $U$ test. Data on categorical variables are presented as proportions, and differences between groups were analyzed with Pearson's chi-squared or Fishers' exact test as appropriate.

The logistic regression model was used in order to assess clinical covariates associated with pathological Gleason upgrading. In the model, variables were entered as continuous or categorical with dichotomy. Moreover, the continuous variables which were categorized into dichotomy included PSA, which was coded as $\mathrm{PSA}>5 \mathrm{ng} / \mathrm{ml}$ versus $\mathrm{PSA} \leq 5 \mathrm{ng} / \mathrm{ml}, \mathrm{P}+$, which was coded as $\mathrm{P}+>0.20$ versus $\mathrm{P}+\leq 0.20$. We chose a threshold of $\mathrm{P}+=0.20$ because of limiting the analysis to a number of positive cores $\leq$ 3 , (i) the product $0.20 \times 12$ cores $=2.4$ positive cores and (ii) the product $0.20 \times 14$ cores $=2.8$ cores. The pathological variables $(\mathrm{V}+, \mathrm{pT})$ were separately analyzed in the model. The goodnessof-fit of the clinical predictive model was assessed by using the Hosmer-Lemeshow test.

All tests are two-sided with $\mathrm{p}<0.05$ considered to indicate statistical significance.

\section{Results}

Patients who were staged as low-risk PCa included 170 out of 438 cases $(38.8 \%)$, as shown in figure 1 . In the surgical specimen, tumor upgrading was detected in 111 patients $(65.3 \%)$ of which $72(42.3 \%)$ had pGP $=3$ +4 (prognostic grade Group II), $27(15.9 \%)$ pGP $=4+3$ (prognostic grade Group III), and $12(7.1 \%)$ pGP $=4+4$ (prognostic grade Group IV). The difference of upgraded biopsies between our institution (39 cases, 68.5\%) and other centers (72 cases, $63.7 \%$ ) was not significant. The basic statistics of clinical and pathological variables are summarized in table 1 .

On univariate analysis, PSA, prostate volume, and $\mathrm{P}+$ achieved statistical significance (table 2). Patients who had their biopsies upgraded had higher median levels of PSA and $\mathrm{P}+$. and lower median levels of prostate volume. Table 3 shows the results of the logistic regression models of covariates associated with tumor upgrade. As shown, only PSA and P+ maintained significance on the multivariate analysis. Patients with higher PSA and $\mathrm{P}+$ values were more likely to be upgraded, with corre-
Table 1. Summary statistics of the patient population $(n=170)$ a) Continuous variables

\begin{tabular}{lcccl}
\hline Statistics & Mean & SD & Median & Range \\
\hline Age, years & 73.76 & 6.02 & 64.0 & $46-75$ \\
BMI, kg/m & 26.6 & 3.02 & 26.4 & $20-42$ \\
PSA, ng/ml & 5.9 & 1.9 & 5.7 & $0.75-9.92$ \\
PV, mL & 41.3 & 15.8 & 40.0 & $15-120$ \\
P+, prop & 0.28 & 0.15 & 0.28 & $0.05-0.78$ \\
V+, \% & 15.8 & 12.13 & 15.0 & $2-70$ \\
W, gr & 55.8 & 19.3 & 51.0 & $13-130$ \\
\hline
\end{tabular}

b) Categorical variables

\begin{tabular}{crr}
\hline Statistics & $\mathrm{n}$ & $\%$ \\
\hline cT & & \\
$1 \mathrm{c}$ & 150 & 88.2 \\
$2 \mathrm{a}$ & 20 & 11.8 \\
pT & & \\
$2 \mathrm{a}$ & 17 & 10.0 \\
2b & 2 & 1.2 \\
$2 \mathrm{c}$ & 130 & 76.5 \\
$3 \mathrm{a}$ & 15 & 8.8 \\
$3 \mathrm{~b}$ & 6 & 3.5 \\
pN & & 11.2 \\
0 & 19 & 88.8 \\
X & 151 & 34.7 \\
pGS & & 58.2 \\
6 & 59 & 7.1 \\
7 & 99 & 34.7 \\
8 & 12 & 42.4 \\
pG & & 15.9 \\
1 & 59 & 7.1 \\
2 & 72 & 91.2 \\
3 & 27 & \\
4 & 12 & \\
Surgery & 155 & \\
RARP & & \\
RRP & & \\
\hline
\end{tabular}

$\mathrm{PV}=$ Prostate volume; $\mathrm{P}+=$ proportion of biopsy positive cores; $\mathrm{V}+=$ percentage of cancer related to volume of the prostate; $\mathrm{W}=$ prostate weight; $\mathrm{cT}=$ clinical tumor stage; $\mathrm{pT}=$ pathological tumor stage; $\mathrm{pN}=$ pathological lymph node stage; $\mathrm{pGS}=$ pathologic Gleason Score; $\mathrm{pG}=$ pathologic grade group; RARP $=$ robot assisted radical prostatectomy; $\mathrm{RRP}=$ retropubic radical prostatectomy.

sponding odd ratios (OR) of 1.32 (95\% confidence interval, (CI), 1.09-1.58) for PSA, and OR of 42.51 (95\% CI 3.7-488.17) for P+. Further exploration of the effects were investigated by categorizing and regressing PSA $(\leq$ 
Table 2. Variables associated with tumor upgrading in the low-risk population $(n=170)$

\begin{tabular}{|c|c|c|c|}
\hline \multirow[t]{2}{*}{ Variables } & \multicolumn{2}{|c|}{ Tumor upgrading on the surgical specimen } & \multirow[t]{2}{*}{$\mathrm{p}$} \\
\hline & No $(n=59)$ & Yes $(n=111)$ & \\
\hline Age, median (range) & $63.3(52-57)$ & $65.0(46-75)$ & 0.297 \\
\hline PSA, median (range) & $5.5(0.75-9.69)$ & $6.05(2.42-9.92)$ & 0.021 \\
\hline PV, median (range) & $40.0(16-120)$ & $39.0(15-110)$ & 0.038 \\
\hline $\mathrm{P}+$, median (range) & $0.17(0.05-0.60)$ & $0.29(0.06-0.78)$ & 0.004 \\
\hline $\mathrm{cT}$ & & & 0.141 \\
\hline $1 \mathrm{c}, \mathrm{n}(\%)$ & $55(36.7)$ & $95(63.3)$ & \\
\hline $2 \mathrm{a}, \mathrm{n}(\%)$ & $4(20)$ & $16(80)$ & 0.036 \\
\hline \multicolumn{4}{|l|}{ pT } \\
\hline$=2$ & $56(37.6)$ & $93(62.4)$ & \\
\hline$>2$ & $3(14.3)$ & $18(85.7)$ & \\
\hline
\end{tabular}

$\mathrm{PV}=$ Prostate volume; $\mathrm{P}+=$ proportion of biopsy positive cores; $\mathrm{V}+=$ percentage of cancer related to volume of the prostate; $\mathrm{W}=$ prostate weight; $\mathrm{cT}=$ clinical tumor stage; $\mathrm{pT}=$ pathological tumor stage.

Table 3. Logistic regression models of covariates predicting tumor upgrading

\begin{tabular}{lrrrr}
\hline Covariates & \multicolumn{1}{l}{ OR } & \multicolumn{2}{c}{$95 \%$ CI } & $\mathrm{p}$ \\
\cline { 3 - 4 } & & Lower & Upper & \\
\hline Univariate model & & & & \\
$\quad$ PSA & 1.276 & 1.071 & 1.520 & 0.006 \\
PV & 0.982 & 0.864 & 1.001 & 0.060 \\
$\quad$ P+ & 27.254 & 2.698 & 275.284 & 0.005 \\
Multivariate models & & & & \\
$\quad$ PSA & 1.320 & 1.098 & 1.586 & 0.003 \\
P+ & 42.519 & 3.703 & 488.176 & 0.003 \\
$\quad$ PSA $>5$ & 2.186 & 1.110 & 4.305 & 0.024 \\
P+> 0.20 & 2.715 & 1.394 & 5.287 & 0.003 \\
\hline
\end{tabular}

$\mathrm{PV}=$ Prostate volume; $\mathrm{P}+=$ proportion of biopsy positive cores.

5.0 vs. $>5.0 \mathrm{ng} / \mathrm{ml})$ and $\mathrm{P}+(\leq 0.20$ vs. $>0.20)$. By using the lowest value as the referent category, the OR of PSA $>5 \mathrm{ng} / \mathrm{ml}$ was $1.32(95 \% \mathrm{CI} 1.11-4.30)$ and the OR of P+ $>0.20$ was 2.71 (95\% CI 1.39-5.28).

The Hosmer-Lemeshow goodness-of-fit was not significant $(\mathrm{p}=0.60)$ thus indicating that our model well fit these data.

According to the results of the multivariate logistic regression model, the population of patients with low-risk PCa were stratified, according to the upgrading risk, into

Low-Risk Prostate Cancer and Tumor Upgrading
Table 4. Clincal risk classes associated with tumor upgrading in the low-risk prostate cancer population $(n=170)$

\begin{tabular}{llll}
\hline Risk & \multicolumn{2}{c}{ Tumor upgrading } & Total \\
\cline { 2 - 3 } & No $(\mathrm{n}=59)$ & Yes $(\mathrm{n}=111)$ & \\
\hline A $(\mathrm{n}, \%)$ & $12(20.3)$ & $10(9.0)$ & $22(12.9)$ \\
B (n, \%) & $19(32.2)$ & $23(20.7)$ & $42(24.7)$ \\
C $(\mathrm{n}, \%)$ & $15(25.4)$ & $22(19.8)$ & $37(21.8)$ \\
D $(\mathrm{n}, \%)$ & $13(22.0)$ & $56(50.5)$ & $69(40.6)$ \\
\hline
\end{tabular}

4 classes which were ranked as follows: (i) very low risk with $\mathrm{PSA} \leq 5 \mathrm{ng} / \mathrm{ml}$ and $\mathrm{P}+\leq 0.20$ (class A), (ii) low risk with PSA $>5 \mathrm{ng} / \mathrm{ml}$ and $\mathrm{P}+\leq 0.20$ (class $\mathrm{B}$ ), (iii) intermediate risk with PSA $\leq 5 \mathrm{ng} / \mathrm{ml}$ and $\mathrm{P}+>0.20$ (class C), and (iv) high risk with PSA $>5 \mathrm{ng} / \mathrm{ml}$ and $\mathrm{P}+>0.20$ (class D).

The results of the clinical classes (A to D) are depicted in figure 2 and summarized in table 4 . Figure 2 shows the percentages of upgraded and not upgraded tumors of the D'Amico low-risk PCa population when classified into the 4 groups by $\mathrm{P}+(\leq 0.20$ vs. $>0.20)$ and $\mathrm{PSA}(\leq 5$ vs. $>5 \mathrm{ng} / \mathrm{ml})$. The sum of the percentages of the upgraded tumors (green columns) is $100 \%$ and the sum of the blue columns (not upgraded tumors) is $100 \%$. As shown (fig. 2 and table 4), the percentage of upgraded tumors was extremely low in class A (9\%) and extremely high in class D (50.5\%). Upgrading rates of class B and C were 


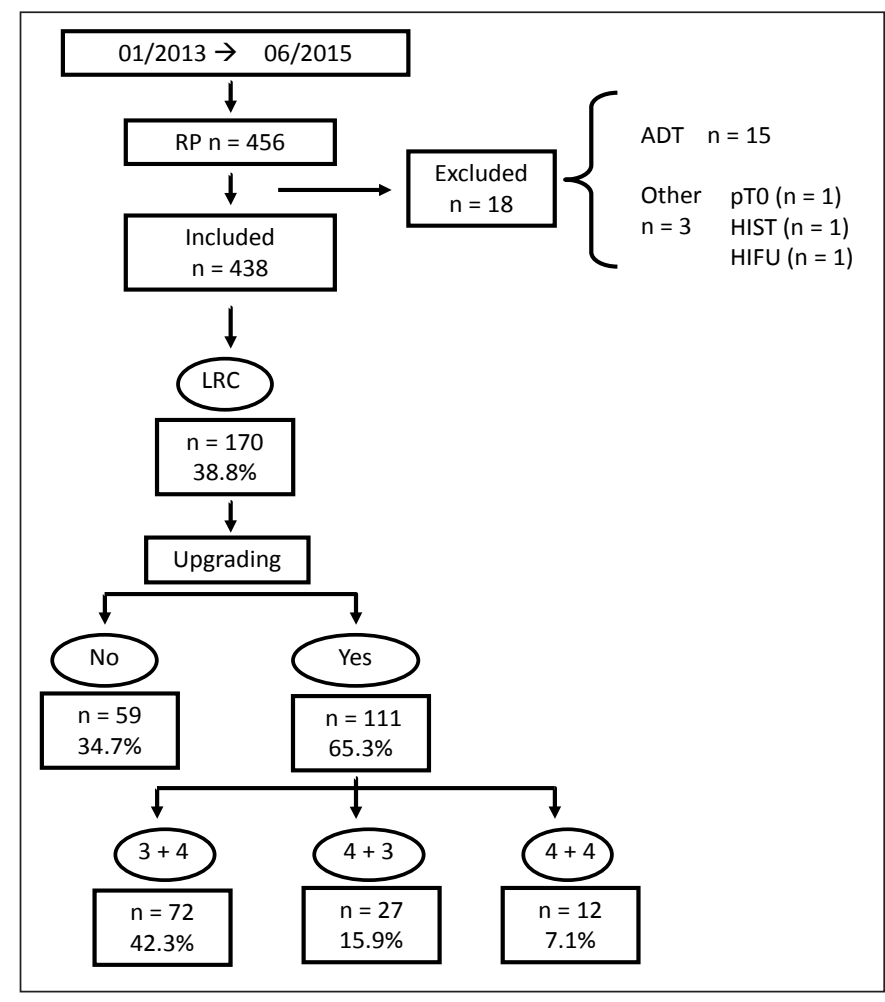

Fig. 1. Diagram showing tumor upgrading of the low-risk $\mathrm{PCa}$ population after RP. (LRC = Low-risk $\mathrm{PCa} ; \mathrm{ADT}=$ androgen deprivation therapy).

both around $20 \%$. Figure 3 is a diagram showing the percentages of upgraded and not upgraded tumors of the D'Amico low-risk prostate cancer population classified by $\mathrm{P}+(<0.20 \mathrm{vs} . \leq 0.20)$ and PSA $(>5 \mathrm{vs} . \leq 5 \mathrm{ng} / \mathrm{ml})$ and related to tumor extension of the prostatectomy specimen $(\mathrm{V}+$, percentage of tumor mass related to the volume of the prostate gland). As illustrated, the 4 classes and relative clusters of upgraded and not upgraded cancers are clearly outlined.

\section{Discussion}

In low-risk organ confined prostate cancer, treatment options include active surveillance, RP, and radiotherapy. Active surveillance is the preferred disease management strategy in low-risk PCa with a low volume disease, while active treatments including RP and radiotherapy are indicated in a higher volume disease. However, low-risk prostate cancer is a heterogeneous population and prostate biopsies can underestimate the true grade of the cancer when compared to prostatectomy specimens as was

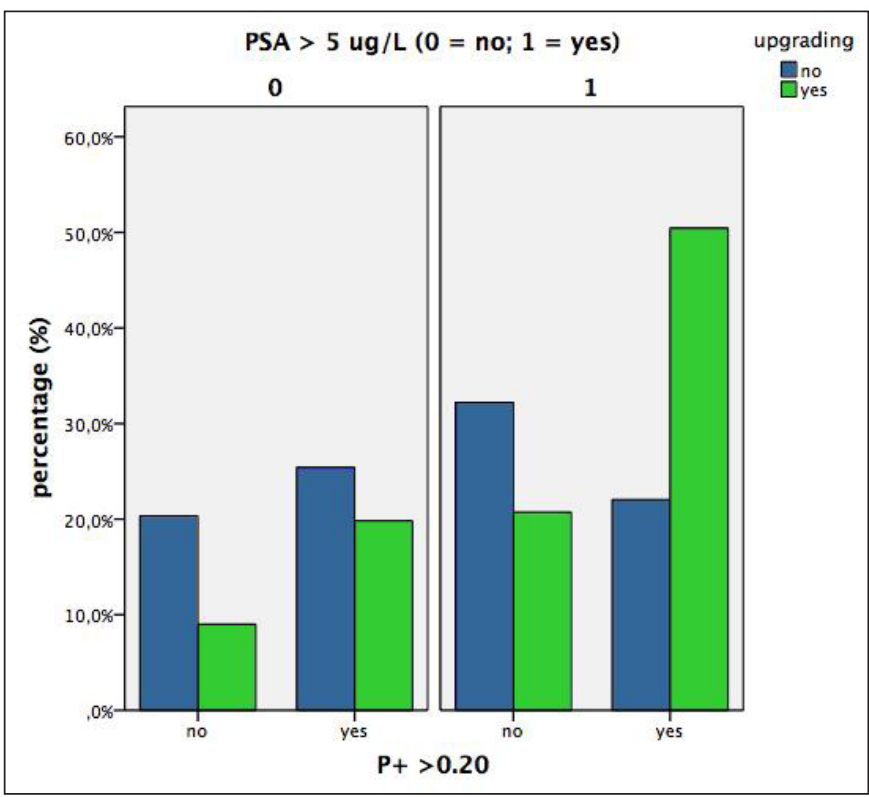

Fig. 2. Diagram showing percentages of upgraded and not upgraded tumors in low-risk prostate cancer patients when classified in 4 groups by $\mathrm{P}+(>0.20 \mathrm{vs} . \leq 0.20)$ and $\mathrm{PSA}(>5 \mathrm{vs} . \leq 5 \mathrm{ng} / \mathrm{ml})$.

reported in past series referring to the previous Gleason score system [13-16]. Recently, in a large contemporary series referring to the modified Gleason score system, it was shown that there is still a wide variation of tumor upgrading which ranges between 43 and $63.8 \%$ [17, 18]. In our study, low-risk PCa, which included $38.8 \%$ of the operated cases, tumor upgrade was detected in $65.3 \%$ of the surgical specimens. Moreover, the upgraded rates did not show any difference between biopsies performed in our institution $(68.4 \%)$ and those performed elsewhere $(63.7 \%)$ which included $66.5 \%$ of the cases.

In daily practice, when dealing with low-risk PCa, it is important for the urologist and the radiation oncologist to know clinical predictors associated with Gleason score upgrading on surgical pathology in order to identify a subset of patients who are likely to have more aggressive disease which needs more appropriate treatment. In contemporary series, it was shown that independent predictors of tumour upgrading in low-risk PCa include non -white race [17], older age [17, 18], higher PSA [17, 18], higher proportion of positive cores, and tumor involvement greater than $50 \%$ in each core [18]. Our investigation demonstrated that higher PSA and higher proportion of positive cores $(\mathrm{P}+)$ were independent predictors of tumor upgrading in the surgical specimen in which the latter showed a stronger association $(\mathrm{OR}=42.51$; 


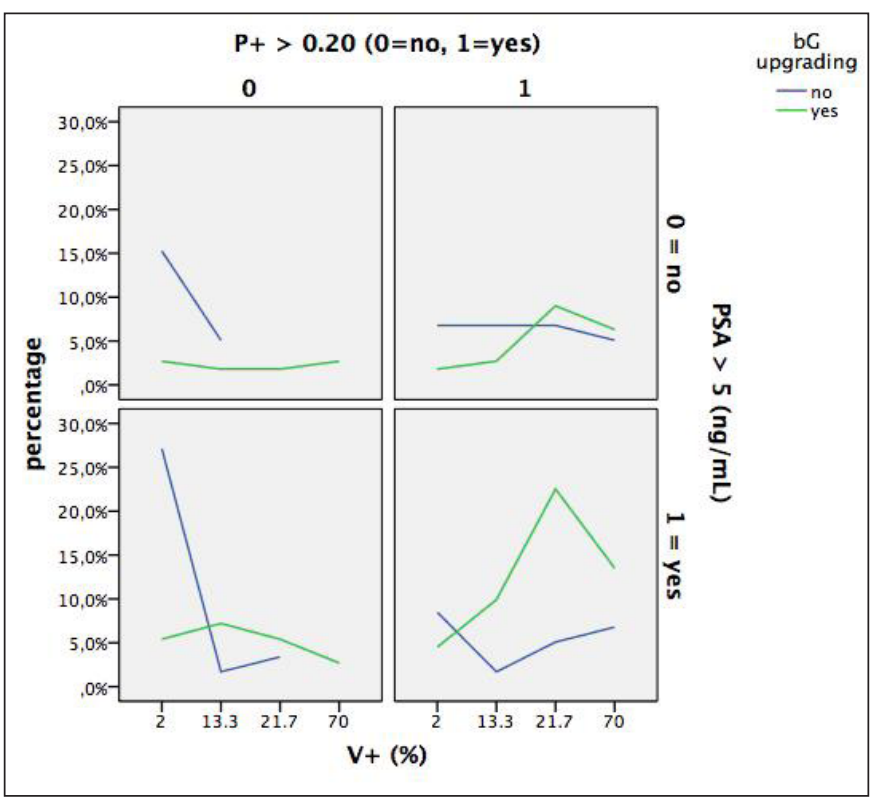

Fig. 3. Diagram showing percentages of upgraded and not upgraded tumors in low-risk PCa patients classified by $\mathrm{P}+(<0.20$ vs. $\leq 0.20)$ and PSA ( $>5 \mathrm{vs} . \leq 5 \mathrm{ug} / \mathrm{L})$ and related to tumor extension of the prostatectomy specimen $(\mathrm{V}+$, percentage of the tumor mass related to the volume of the gland).

95\% CI 3.70-488.17) than the former (OR $=1.32 ; 95 \%$ CI 1.09-1.58). Further exploration of the effect of these variables was explored by regressing cutoffs of PSA $(\leq$ 5.0 vs. $>5 \mathrm{ng} / \mathrm{ml})$ and $\mathrm{P}+(\leq 0.20$ vs. $>0.20)$.

By using the lowest cutoff as the reference category, the OR of PSA $>5 \mathrm{ng} / \mathrm{ml}$ was 2.18 (95\% CI 1.11-4.30) and $\mathrm{P}+>0.20$ was 2.71 (95\% CI 1.39-5.28), thus indicating that much of the significant effect of PSA and $\mathrm{P}+$ were mediated at increasing values beyond the cutoff levels. Thus we have demonstrated that patients with low-risk disease have a higher probability of harboring an occult pattern of higher-grade disease if their PSA value is elevated (especially $>5.0 \mathrm{ng} / \mathrm{ml}$ ) and/or if the proportion of positive biopsy cores is higher than 0.20 . A high PSA value as an indicator of high-grade disease has been demonstrated and is biologically intuitive, as one would expect more PSA secretion from more aggressive tumors $[19,20]$. Higher proportions of positive biopsy cores are associated with higher Gleason scores because $\mathrm{P}+$ is strongly correlated to tumor load $(\mathrm{V}+)$ with a high Pearson's correlation coefficient $(r=0.40 ; p<0.0001)$.

In the prospective toward advanced management strategies for low-risk PCa, our study has effective relevance. We have identified preoperative clinical predictors that

Low-Risk Prostate Cancer and Tumor Upgrading can facilitate risk stratification and a tool, in the form of a diagram, which can aid physicians in stratifying lowrisk PCa patients into increasing upgrading risk groups which rank from A to D (table 4, fig. 2 and 3). As shown in figure 2 , the percentage of upgraded tumors were extremely low in class A (9\%), extremely high in class D $(50.5 \%)$, and moderate (around 20\%) in both class B and C. However, as illustrated in figure 3 , the main feature differentiating between class $\mathrm{B}$ and $\mathrm{C}$ was the load of the tumor which was clearly more extensive in class $\mathrm{C}$. Interestingly, our diagram identified class $\mathrm{D}$ as showing the highest risk of tumor upgrading (50.5\% of cases). We suggest that low-risk PCa with PSA $>5 \mathrm{ng} / \mathrm{ml}$ and $\mathrm{P}+>0.20$ represent a high-risk subgroup of tumor upgrading and needs, before making any decision of active treatments (RP or radiotherapy), tumor grade reclassification by performing re-biopsies. If tumor upgrading is confirmed, the patient is reclassified into the D'Amico's intermediate or high-risk classes which need more advanced staging procedures (multiparametric magnetic resonance imaging, mpMRI, CT, positron emission tomography) and modified treatment strategies including the possibility of not considering nerve sparing surgery, of planning extended lymph node dissection in high-risk cases, or in intermediate-risk cases when indicated by specific nomograms. Also, patients falling into class $\mathrm{C}$ need more advanced local staging investigation by $\mathrm{mp}$ MRI which will suggest the possibility of considering repeated biopsies in order to reclassify the grade of the tumor. In recent years, mpMRI of the prostate was shown to be an effective tool for identifying areas of suspicion which correlate with cancer extension [21, 22].

In low-risk PCa patients under AS criteria including PSA $<10 \mathrm{ng} / \mathrm{ml}$, cT1c-2a, bGP $=3+3$, and number of positive cores less than or equal to 3 , immediate repeated biopsies have been recommended because of the high risk of upgrading which has been detected in $17.3 \%$ of cases [23]. Interestingly, in our study, low-risk $\mathrm{PCa}$ including classes A and B represents subgroups in which active surveillance is the appropriate treatment. However, class B is at a higher risk of tumor reclassification because of the increased risk of cancer upgrading (20.7\%) than class A (9\%). Although both classes A and $\mathrm{B}$ have a proportion of positive cores less then or equal to 0.20 , the difference relates to the PSA load which is an indicator of high-grade disease with increased PSA secretion $[19,20]$.

As a theory, in active surveillance patients, short-time repeated biopsies might be indicated in class B because of the high risk of tumor reclassification. 
There are limits in our study. First, not all biopsies were performed at our institution which included only $33.5 \%$ of the cases. However, although $66.5 \%$ of the patients had biopsies performed elsewhere, all RP specimens were assessed by our dedicated pathologists who did not find any difference of upgrading rates in pathological specimens between biopsies performed in our unit or elsewhere. Second, the density of PSA was not evaluated because tumor volume was not significantly associated with upgrading, as patients with low-grade disease at biopsy tend to have larger prostates [24]. Third, we did not evaluate the role of re-biopsy on tumor upgrading. Fourth, although we have presented a diagram that may serve as a useful tool when evaluating low-risk PCa patients, it is not a validated nomogram. However, our diagram represents the first step leading to validated nomograms which will be required in the future and be computed according to the modified classification of the Gleason score system which will cluster the patient population into more accurate prognostic risk groups [5-8]. Despite these limitations, we feel that our study shows important results because we have provided clinicians with clinical factors (PSA and $\mathrm{P}+$ ) associated with upgrading of low-risk disease. Moreover, our diagram is a useful tool which can help in making clinical decisions. By facilitating identification of individuals who are at high risk of upgrading from low-risk disease status, clinicians decrease the risk of inappropriate treatment of patients with undetected high-grade cancer.

\section{Conclusion}

Patients diagnosed with low-risk PCa at biopsy are a heterogeneous population because they include subsets with undetected higher-grade disease. Despite D'Amico's low-risk criteria, a relevant proportion of patients was upgraded at final pathology and a nonnegligible proportion of patients harbored intermediate-risk and high-risk characteristics at final pathology. In this patient population, significant clinical predictors of upgrading included the PSA value and proportion of positive cores. These variables were categorized, related to the load of the tumor of the specimen, and then classified into a diagram that clusters the population into risk subgroups. The diagram can be used adjunctively when making clinical decisions and when considering reclassification of disease by repeated biopsies. In low-risk PCa, the diagram identifies an upgrading high-risk group in which we recommend repeated biopsies in order to reclassify the grade of the tumor and to reassess the clinical risk category.

\section{References}

1 D'Amico AV, Whittington R, Malkowicz SB, Schultz D, Blank K, Broderick GA, Tomaszewski JE, Renshaw AA, Kaplan I, Beard Cj, Wein A: Biochemical outcome after radical prostatectomy, external beam radiation therapy, or interstitial radiation therapy for clinically localized prostate cancer. JAMA 1998; 280:969-974.

2 Dahabreh IJ, Chung M, Balk EM, YU WW, Mathew P, Lau J, Ip S: Active surveillance in men with localized prostate cancer: a systematic review. Ann Intern Med 2012;156:582590 .
3 Morash C, Tey R, Agbassi C,Klotz L, McGowan T, Srigley J, Evans A: Active surveillance for the management of localized prostate cancer: guideline recommendations. Can Urol Assoc J 2015;9:171-178.

4 Moyer VA, U.S. Preventive Services Task Force: Screening for prostate cancer: U.S. Preventive Service Task Force recommendation statement. Ann Intern Med 2012;157: 120-134.

5 Epstein JI, Allsbrook WC Jr, Amin MB, Egevad LL, ISUP Grading Committee: The 2005 International Society of Urological Pathology (ISUP) consensus conference on Gleason grading of prostatic carcinoma. Am J Surg Pathol 2005;29:1228-1242.
6 Pierorazio PM, Walsh PC, Partin AW, Epstein JI: Prognostic Gleason grade grouping: data based on the modified Gleason scoring system. BJU Int 2013;111:753-760.

7 Brimo F, Montironi R, Egevad L, Erbersdobler A, Lin DW, Nelson JB, Rubin MA, van der Kwast T, Amin M,Epstein JI: Contemporary grading for prostate cancer: implications for patient care. Eur Urol 2013; 63: 892-901.

8 Epstein JI, Zelefsky MJ, Sjoberg DD, nelson JB, Egevad L, Magi-Galluzzi C, Vickers AJ, Parwani AV, Reuter VE, Fine SW, Eastham JA, Wiklund P, Han m, Reddy CA, Ciezki JP, Nyberg T, Klein EA: A contemporary prostate cancer grading system: a validated alternative to the Gleason score. Eur Urol 2016; 69:428-435. 
9 Liu JJ, Lichtensztajn DY, Gomez SL, Sieh W, Chung BI, Cheng I, Brooks JD: Nationwide prevalence of lymph node metastases in Gleason Score $3+3=6$ prostate cancer. Pathology 2014;46:306-310.

10 D'Amico AV, Renshaw AA, Arsenault L, Schultz D, Richie JP: Clinical predictors of upgrading to Gleason grade 4 or 5 disease at radical prostatectomy: potential implications for patient selection for radiation and androgen suppression therapy. Int J Radiat Oncol Biol Phys 1999;45:841-846.

11 Fukagai T, Namiki T, namiki H, Carlile Rg, Shimada M, Yoshida H: Discrepancies between Gleason score of needle biopsy and radical prostatectomy specimens. Pathol Int 2001;51:364-370.

12 Kulkarni GS, Lockwood G, Evans A, Toi A, Trachtenberg J, Jewett MA, Finelli A, Fleshner NE: Clinical predictors of Gleason score upgrading: implications for patients considering watchful waiting, active surveillance, or brachytherapy. Cancer 2007;109:2432-2438.

13 Mitsuzuka K, Narita S, Koie T, Kaiho Y, Tsuchiya N, Yoneyama T, Kakoi N, Kawamura S, Tochigi T, Habuchi T, Ohyama C, Arai Y: Pathological and biochemical outcomes after radical prostatectomy in men with low-risk prostate cancer meeting the prostate cancer international: active surveillance criteria. BJU Int 2013;111:914-920.

14 Chun FK, Briganti A, Shariat SF, Graefen M, Montorsi F, Erbersdobler A, Steuber T, Salonia A, Currlin E, Scattoni V, Friedrich MG, Schlomm T, Haese A, Michl U, Colombo R, heinzer H, Valiquette L, Rigatti P, Roehrborn $\mathrm{Cg}$, Huland H, Karakiewicz PI: Significant upgrading affects a third of men diagnosed with prostate cancer: predictive nomogrm and internal validation. BJU Int 2006;98: 329-334.
15 Isariyawongse BK, Sun L, Banez LL, Robertson C, Polascik TJ, Maloney K, Donatucci C, Albala D, Mouraviev V, Madden JF, Moul JW: Significant discrepancies between diagnostic and pathologic Gleason sums in prostate cancer: the predictive role of age and prostate-specific antigen. Urology 2008;72: 882-886.

16 Tilki D, Schlenker B, John M, Buchner A, Stanislaus P, Gratzke C, Karl A, Tan GY, Ergun S, Tewari Ak, Stief CG, Seitz M, Reich O: Clinical and pathologic predictors of Gleason sum upgrading in patients after radical prostatectomy: results from a single institution series. Urol Oncol 2011;29:508-514.

17 Caster JM, Falchook AD, Hendrix LH, Chen RC: Risk of pathologic upgrading or locally advanced disease in early prostate cancer patients based on biopsy Gleason score and PSA: a population-based study of modern patients. Int J Radiat Oncol boil Phys 2015;92: 244-251.

18 Schiffmann J, Wenzel p, Salomon G, Budaus 1, Schlomm T, Minner S, Wittmer C, Kraft S, Krech T, Steurer S, Sauter G, Beyer B, Boehm K, Tilki D, Michl U, Huland H, Graefen M, karakiewicz PI: Heterogeneity in D'Amico classification-based low-risk prostate cancer: differences in upgrading and upstaging according to active surveillance eligibility. Urol Oncol 2015;33:329.e13-19.

19 Thompson IM, Chi C, Ankerst DP, Goodman PJ, Tangen CM, Lippman Sm, Lucia MS, Parnes HL, Coltman CA Jr: Effect of finasteride on the sensitivity of PSA for detecting prostate cancer. J Natl Cancer Inst 2006;98: 1128-1133.
20 Porcaro AB, Monaco C, Romano M, Petrozziello A, Rubilotta E, lacola V, Sava T, Ghimenton C, Caruso B, Antoniolli SZ, Migliorini $\mathrm{F}$, Comunale L: Investigative clinical study on prostate cancer part II: on the role of the pretreatment total PSA to free testosterone ratio as a marker assessing prostate cancer prognostic groups after radical retropubic prostatectomy. Urol Int 2010;85:152-158.

21 Mendhiratta N, Meng X, Taneja SS: Using multiparametric MRI to "personalize" biopsy for men. Curr Opin Urol 2015;25:498-503.

22 Porcaro AB, Borsato A, Romano M, Sava $\mathrm{T}$, Ghimenton C, Migliorini F, Monaco C, Rubilotta E, Antoniolli SZ, lacola V, Montemezzi S: Accuracy of preoperative endo-rectal coil magnetic resonance imaging in detecting clinical under-staging of localized prostate cancer. World J Urol 2013;31:12451251.

23 Berglund RK, Masterson TA, Eggener SE, Eastham JA, Guillonneau BD: Pathological upgrading and upstaging with immediate repeat biopsy in patients eligible for active surveillance. J Urol 2008;180:1964-1967.

24 Porcaro AB, Novella G, Molinari A, Terrin A, minja A, De Marco V, Martignoni G, Brunelli M, Cerruto MA, Curti P, Cavalleri S, Artibani W: Prostate volume index and chronic inflammation of the prostate type IV with respect to the risk of prostate cancer. Urol Int 2015;94:270-285. 